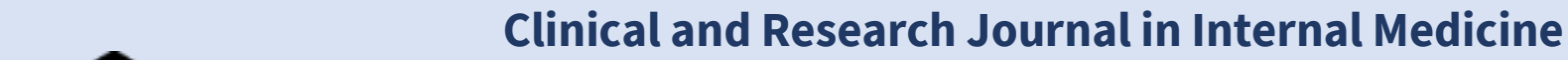

\section{The Diagnosis Algorithm of Chronic Hypokalemia in Bartter Syndrome and Gitelman Syndrome: A Case Report}

Ro'di Nur Fajiri ${ }^{1}$, Isbandiyah ${ }^{1}$, Gusti Galang Pambudi ${ }^{1}$

${ }^{1}$ University of Muhammadiyah Malang Hospital, Malang, East Java-Indonesia

ARTICLE INFO

Corresponding Author:

Ro'di Nur Fajri, University of

Muhammadiyah MalangHospital,

Malang, East Java-Indonesia

Email:

rodinurfajri19@gmail.com

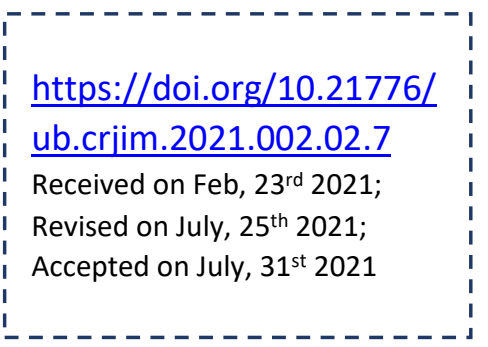

ABSTRACT

Introduction: Hypokalemia is common disorder characterized by low plasma potassium levels ( $<3.5 \mathrm{mEq} / \mathrm{L}$ ). Hypokalemia can be caused by genetic disorders. Bartter syndrome and Gitelman syndrome are rare genetic disorders that cause damage to the tubular kidneys. The cause of hypokalemia must be determined by analyzing the diagnosis algorithm of hypokalemia.

Case Illustration: A 27-year-old woman was brought to the emergency room with complaints of weakness in both legs since 1 day ago. Obtained a history of chronic hypokalemia since 5 years ago. No history of thyroid disease, and never taking diuretic drugs. The patient is calm. Vital signs: BP: $110 / 60$, regular pulse $88 \mathrm{x} /$ minute, temperature: $36.7^{\circ} \mathrm{C}$, respiratory rate $14 \mathrm{x} /$ minute, oxygen saturation $99 \%$ in room air. ECG showed Normal sinus rhythm with normal T wave. Laboratory findings showed severe hypokalemia with plasma potassium $1.7 \mathrm{mEq} / \mathrm{L}$, increased urine potassium ( $71.1 \mathrm{mmol} / 24$ hours), increased urine sodium $306 \mathrm{mmol} / 24$ hours, and increased urine chloride (342 mmol/24 hours), plasma magnesium levels were normal (1.91 $\mathrm{mg} / \mathrm{dL}$ ). $\mathrm{KCl}$ infusion was given to correct electrolyte imbalance condition.

Discussion: Several examinations must be performed to confirm the cause of hypokalemia condition. The diagnosis of this patient was suspected to lead to Bartter syndrome and Gitelman syndrome, because there was an increase in urinary potassium excretion, normotensive conditions, no suspicion of metabolic acidosis, and no symptoms of nausea and vomiting and no history of diuretic drugs usage.

Keywords: Hypokalemia, Bartter syndrome, Gitelman syndrome

\section{N T R O D U C T I O N}

Hypokalemia is a common disorder characterized by low plasma potassium levels (<3.5 mEq/L). ${ }^{(1)}$ Hypokalemia can be caused by abnormal potassium loss (drug use, gastrointestinal loss, kidney loss), transcellular changes (use of insulin drugs, beta agonists, alkalosis, thyrotoxicosis, etc.), inadequate intake (anorexia, dementia), as well as pseudo hypokalemia (delayed examination of samples, and significant leukocytosis $(>75,000$ cells/mm3). ${ }^{(2)}$ Hypokalemia can also be caused by genetic disorders. Bartter syndrome and Gitelman syndrome are congenital disorders caused by mutations of several genes that are

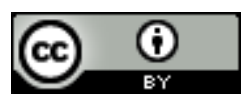

Fajri RN, Isbandiyah, PambudiGG. Case Report: Chronic Hypokalemia with

Suspected Bartter Syndrome and Gitelman Syndrome, Focus on Diagnosis

Algorithm. Clinical and Research Journal in Internal Medicine. 2:2(2021):216-221.

DOI:https://doi.org/10.21776/ub.crjim.2021.002.02.7 
inherited autosomal recessive and impact on kidney tubular damage related to sodium, potassium, and chloride regulation. The incidence of Bartter syndrome is quite rare, about 1: $1,000,000$ of the total population. ${ }^{(3)}$ while Gitelman syndrome occurs in approximately 1: 40.000 in Caucasian individuals. ${ }^{(4)}$

The main symptom of Bartter syndrome and Gitelman syndrome is chronic hypokalemia, which can cause headaches, dizziness, constipation, cramps, and muscle weakness. ${ }^{(5)}$ In some individuals, Bartter syndrome and Gitelman syndrome can result in a significant electrolyte imbalance. This condition can cause irregular heartbeats (arrhythmias) which can lead to sudden cardiac arrest. ${ }^{(6)}$ Hypokalemia conditions need to be found the underlying cause, so that the therapy can be optimal. It can be determined by analyzing the diagnosis algorithm of hypokalemia. Several examinations must be performed to confirm the diagnosis. In this case report, we will discuss a case of chronic hypokalemia on a young female patient with suspected renal tubulopathy, with a focus on the algorithm that can be taken in establishing the cause of the diagnosis of hypokalemia.

\section{CASE I L L U S T RA T I O N}

A 27-year-old woman was brought to the Emergency Room at the University of Muhammadiyah Malang Hospital with complaints of weakness in both legs since 1 day ago. The weakness is felt so severe that the patient cannot walk. This condition does not improve with rest. In addition, the patient also complained of nausea, and had constipationsince 2 days ago. The patient had a history of recurrent hypokalemia since 5 years ago. Hospitalization episodes are quite frequent. Almost once a month patient is hospitalized for hypokalemic conditions with unknown cause. There was no history of thyroid disease, and the patient had never taken diuretic drugs. On physical examination, the patient is in a calm condition. Vital signs were: BP: $110 / 60$, pulse rate is regular $88 x /$ minute, body temperature: $36.7^{\circ} \mathrm{C}$, respiratory rate $14 x /$ minute and oxygen saturation $99 \%$ on room air. The results of the EKG show a normal sinus rhythm with a heart rate of $88 \mathrm{x} /$ minute, regular, and normal $T$ waves. The results of laboratory tests showed that complete blood count was within normal limits, while on electrolyte examination, the plasma potassium level was quite low $(1.7 \mathrm{mEq} / \mathrm{L})$. Previous history, in 2016 the patient had an ultrasound, $\mathrm{MRI}$, and urine electrolyte examination. From the results of ultrasound examination, it was found that focal ectasis was found on the right kidney superior and inferior pole, and complex cyst on the superior pole of the left kidney. MRI results did not show mass or enhancement in the right and left adrenal glands. Complex cysts found on the superior pole of the left kidney according to Bosniak IIF criteria. Focal ectasis found on calyx major inferior pole on right kidney, and simple cyst on the superior pole on right kidney according to Bosniak I criteria. From the results of urine electrolyte examination, the value of urine sodium was 306 (40-220) $\mathrm{mmol} / 24$ hours, urine potassium 71.1 (25-125) $\mathrm{mmol} / 24$ hours, and urine chloride 342 (110-250) mmol/24hours. Plasma magnesium levels have also been checked and the results obtained are $1.91(1,58-2,55) \mathrm{mg} / \mathrm{dL}$. This patient has excessive urine sodium and urine potassium excretion, while magnesium levels is within normal limit. The patient was diagnosed with chronic hypokalemia with suspected tubular abnormalities in the kidney leading to Bartter Syndrome and Gitelman Syndrome. After consultation with an internist, the patient received $\mathrm{KCl} 50 \mathrm{mEq}$ infusion therapy within 12 hours and then repeated up to 3 times. For oral 
therapy, the patient got Kalium SustainedRelease (KSR) tablet therapy $3 \times 600 \mathrm{mg}$ a day. In addition, patients also received $1 \times 100 \mathrm{mg}$ spironolactone. Rechecking the serum electrolyte was done after the $\mathrm{KCl}$ infusion therapy was finished. The patient was discharged in a stable condition and had no complaints with the results of plasma potassium $3,7 \mathrm{mEq} / \mathrm{L}$.

\section{I S C U S S I O N}

Hypokalemia is a condition that must be treated immediately. The appearance of warning signs at hypokalemia requires immediate treatment. Conditions that include a warning sign are severe hypokalemia $(<2.5 \mathrm{meq} / \mathrm{L})$, hypokalemia with sudden onset, palpitations, muscle weakness, changes in ECG waves, or the patient has a history of heart disease or underlying hepatic cirrhosis. ${ }^{(2)}$ In this case, a 27-year-old female patient experienced several warning signs such as muscle weakness in both lower extremities which occurred suddenly and got worse since 1 day ago and low Potassium level $(1,7 \mathrm{mEq} / \mathrm{L})$. Gastrointestinal causes of hypokalemia such as low intake, nausea, vomiting, and diarrhea can be excluded. History of drugs that can affect potassium levels such as insulin use, thyroid hormone boosters, beta adrenergic, and diuretics can also be excluded. From the past history and physical examination, the patient was also not hyperthyroid and did not show any metabolic acidosis. The condition of hypokalemia in this patient is suspected to be due to tubulopathy in the kidneys. Investigations such as an electrocardiogram are useful for checking for arrhythmias or other electrolyte abnormalities.

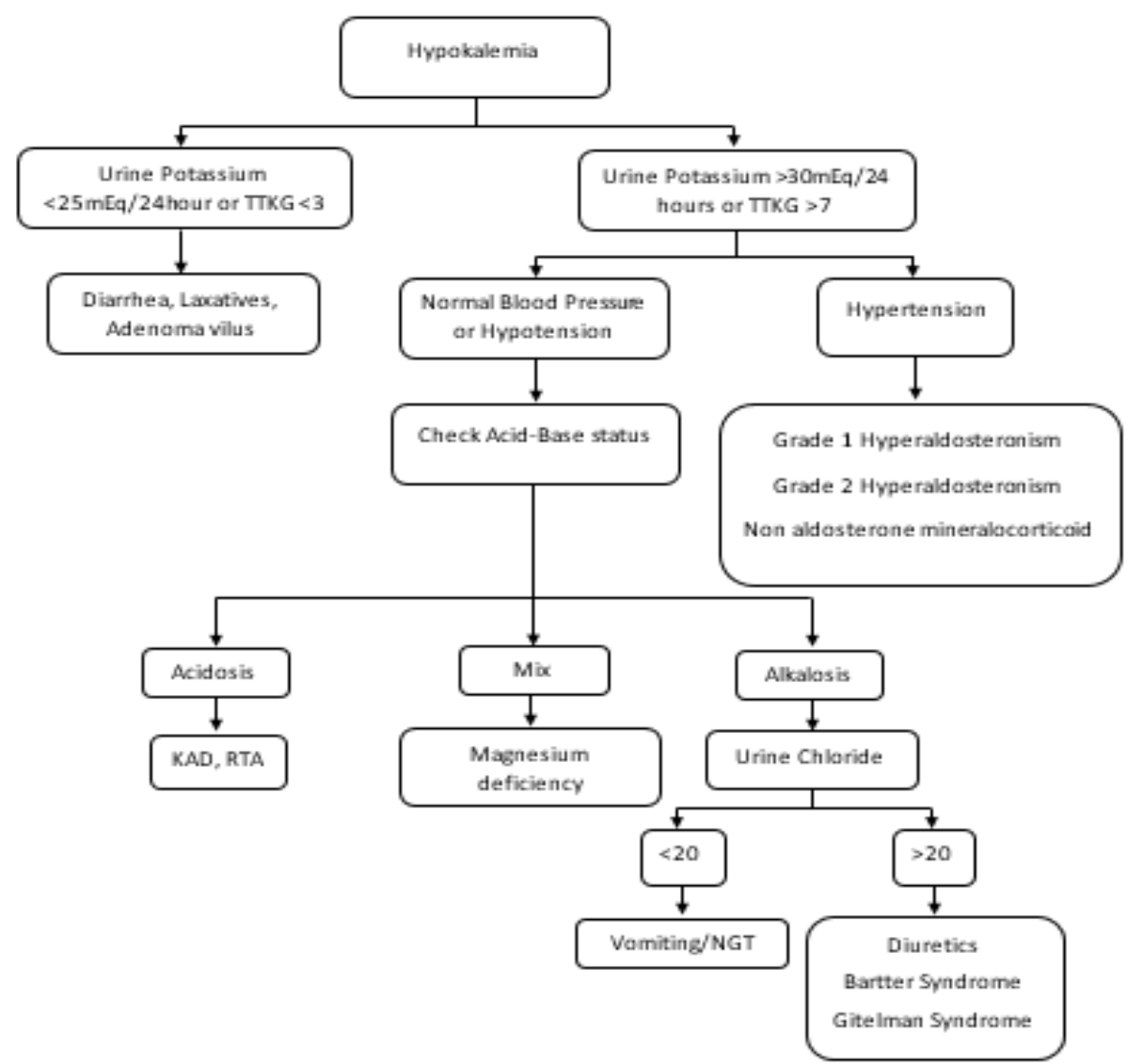

Figure 1. Diagnosis Algorithm of Hypokalemia(6) 
Laboratory tests showed a very low potassium level $(1.7 \mathrm{mEq} / \mathrm{L})$. The cause of the hypokalemia in this patient was determined using urine electrolytes examination. A urine potassium value of more than 30 indicates a leak of potassium from the urine. If urine potassium value is high, it can be evaluated by the patient's blood pressure. In hypertensive patients, hyperaldosteronism is suspected, whereas in normotensive conditions the decreased ability of the kidneys to retain potassium can be divided according to the accompanying acid-base disorders. Metabolic acidosis is usually caused by diabetic ketoacidosis and renal tubular acidosis. Whereas in conditions of metabolic alkalosis, it can be caused by severe vomiting, use of diuretics, or Bartter and Gitelmansyndrome. ${ }^{(7)}$ Blood gas analysis was not examined in this patient so that the patient's acid-base status cannot be determined certainty. However, from the results of the anamnesis and physical examination, she did not show any symptoms leading to metabolic acidosis. The diagnosis is suspected to Bartter syndrome and Gitelman syndrome, because the patient found increased excretion of potassium through urine, normotensive conditions, no suspicion of metabolic acidosis, and no symptoms of nausea and vomiting and no history of using diuretic drugs. The difference between Bartter syndrome and Gitelman syndrome is as follows:

Table 1. Differences between Bartter and GitelmanSyndrome $e^{(4,6,8)}$

\begin{tabular}{|c|c|c|}
\hline Featured & Bartter Syndrome & Gitelman Syndrome \\
\hline Pathophysiology & $\begin{array}{l}\text { Genetic tubular defects ( } S L C 12 A 1, K C N J 1 \text {, } \\
\text { CLCNKA, or BSND genes) in Loop of Henle } \\
\text { sodium chloride transport that produce a } \\
\text { clinical disorder. Appears similar to that } \\
\text { seen with chronic ingestion of a loop } \\
\text { diuretic }\end{array}$ & $\begin{array}{l}\text { Genetic tubular defects } \\
\text { (SLC12A3 or CLCNKB genes) in Distal } \\
\text { tubule sodium chloride transport produce } \\
\text { a clinical disorder. Appears similar to that } \\
\text { seen with chronic ingestion of a thiazide } \\
\text { diuretic }\end{array}$ \\
\hline Location & Ascending thick limb of the loop of Henle & Distal convoluted tubule \\
\hline Urinary calcium excretion & $\begin{array}{l}\text { Normal or increased, commonly with } \\
\text { nephrocalcinosis }\end{array}$ & Decreased \\
\hline Serum magnesium & Normal or decreased & Decreased, sometimes greatly \\
\hline $\begin{array}{l}\text { Renal prostaglandin E2 } \\
\text { production }\end{array}$ & Increased & Normal \\
\hline Usual age at presentation & $\begin{array}{l}\text { Before birth to early childhood, often with } \\
\text { intellectual disability and growth } \\
\text { disturbance }\end{array}$ & Late childhood to adulthood \\
\hline Neuromuscular symptoms & Uncommon or mild & Common \\
\hline
\end{tabular}

From the table above, the point that leads to Bartter syndromein this patient is normal magnesium level. The points that lead to Gitelman syndrome are the usual age at presentation that usually occurs in adult patients and commonly develops neuromuscular disorders such as muscle weakness, spasms, and cramps. The diagnosis that suitable for this patient is more likely leads to Gitelman Syndrome. To certainly distinguish these two syndromes, molecular genetic testing can be performed to detect mutations in specific genes. ${ }^{(6)}$ We can perform molecular genetic testing such as SLC12A1, KCNJ1, CLCNKA, and BSND genesfor Bartter syndrome. Gitelman syndrome can be detected by performing molecular genetic test such as SLC12A3 or CLCNKB genes. ${ }^{(4,6)}$ Currently, it is possible to make diagnosis of Barter and Gitelman in one patient. In Bartter syndrome 
type III, there are similar characteristics with Gitelman syndrome. Some children with Bartter syndrome type III also present with Gitelman phenotype as CLC-NKB found in the distal convoluted tubule and in the connecting tubule. ${ }^{(8)}$ In this case, molecular genetic examination was not examined due to limited facilities.

Results of ultrasound examination, it was found that focal ectasis on the superior and inferior poles of the right kidney, as well as complex cysts on the superior and inferior pole of the left kidney. From the Abdominal MRI results, there was no mass or enhancement in the right and left adrenal glands, complex cysts found on the superior pole of the left kidney according to the Bosniak IIF criteria, Focal ectasis found on calyx major inferior pole on right kidney, and simple cyst on the superior pole on right kidney according to Bosniak I criteria. Chronic hypokalemia is known to induce renal cyst formation in some disease including primary aldosteronism, distal renal tubular acidosis, Liddle disease and apparent mineralocorticoid excess syndrome. ${ }^{(9)}$ Renal cyst formation in Bartter syndrome and Gitelman syndrome rarely reported before. Although the precise mechanism underlying the development of renal cysts in our patient remains unclear, chronic hypokalemia may contribute to cyst development. ${ }^{(9)}$ Bosniak classification can be used to predict the risk of cysts in the kidney to develop into malignancy. Bosniak I cysts are benign, while BosniaklIF cysts are likely to be benign, and very rarely develop into malignancy. ${ }^{(10)}$

$\mathrm{KCl}$ infusion therapy was given at a dose of $50 \mathrm{mEq}$ in $500 \mathrm{cc} 0.9 \% \mathrm{NaCl}$, finished within 12 hours, the administration was repeated up to 3 times. For oral therapy, KSR $3 \times 1$ tablets a day and Spironolactone $1 \times 100 \mathrm{mg}$ were given. Rechecking the serum electrolyte was done after the $\mathrm{KCl}$ infusion therapy was finished. This therapy is in accordance with the theory. In severe hypokalemic conditions (Potassium $<2,5 \mathrm{mEq} / \mathrm{L}$ ) a maximum $\mathrm{KCl}$ can be given at a dose of $60 \mathrm{mEq}$ dissolved in $1000 \mathrm{cc} 0.9 \% \mathrm{NaCl}$ at a speed below $10 \mathrm{mEq} /$ hour. Oral potassium replacement given at a dose of $40-60 \mathrm{mEq}$ can increase potassium levels by $1-1.5 \mathrm{mEq} / \mathrm{L}^{(7,11)}$ Spironolactone is a specific aldosterone antagonist that binds competitively to the aldosterone-dependent sodium-potassium exchange site in the distal tubule. This can increase water excretion and hold potassium. ${ }^{(5)}$ Bartter's syndrome and Gitelman syndrome are usually accompanied by hypomagnesemia. ${ }^{(6)}$ The magnesium level in this patient is normal $(1.91 \mathrm{mg} / \mathrm{d})$, so it does not require additional therapy to correct magnesium levels. Currently, there is no definitive treatment for Bartter and Gitelman syndrome. The treatment is focused on fluid and electrolyte correction. Severity of symptoms (and associated complications) vary from person to person. People with Bartter and Gitelman syndrome must take medications consistently, as prescribed, throughout their lifetime. They also must be careful to maintain an adequate fluid and electrolyte balance. ${ }^{(6)}$

\section{O N C L U S I O N}

Hypokalemia can be fatal and life threatening if not treated immediately. In addition, the cause of hypokalemia must also be known. Tubulopathic disorders of the kidneys such as Bartter Syndrome and Gitelman are very rare, but it is important to know so that the therapy given to patients can be optimal. 


\section{RE F E RE N C E S}

1. Siregar P. GangguanKeseimbangan Air dan Elektrolit. Buku Ajar IlmuPenyakitDalam PAPDI edisi 6. InternaPublishing. 2014

2. Anthony J,Niah W. Potassium Disorders: Hypokalemia and Hyperkalemia. American Family Physician. September 15, 2015. Volume 92, Number $\quad 6 . \quad$ http://www.aafp.org/ afp/2015/0915/p487-s1. html.

3. Cunha TDS, Heilberg IP. Bartter syndrome: causes, diagnosis, and treatment. Int J Nephrol Renovasc Dis. 2018 Nov 9;11:291-301.

doi: 10.2147/IJNRD.S155397. PMID: 30519073; PMCID: PMC6233707].

4. Klemmer PJ. Gitelman Syndrome. National Organization for Rare Disorders (NORD). 2015; http://rarediseases.org/rarediseases/gitelman-syndrome/.

5. Al Shibli A, Narchi H. Bartter and Gitelman syndromes: Spectrum of clinical manifestations caused by different mutations. World J Methodol. 2015;5(2):55-61. Published 2015 Jun 26. doi:10.5662/wjm.v5.i2.55

6. Bockenhauer D. Bartter's Syndrome. National Organization for Rare Disorders (NORD). 2016; http://rarediseases.org/rare-diseases/bartterssyndrome/.
7. Alwi I, Salim S, Hidayat R. Penatalaksanaan di BidangllmuPenyakitDalam Panduan PraktikKlinis. InternaPublishing. 2019

8. LaRosa CJ. Bartter and Gitelman Syndrome. Merck Manual Consumer Version. January 2018. Available at: http://www.merckmanuals.com/professional/pe diatrics/congenital-renal-transportabnormalities/bartter-syndrome-and-gitelmansyndrome

9. Watanabe T, Tajima T. Renal cysts and nephrocalcinosis in a patient with Bartter syndrome type III. 2005. available at: https://link.springer.com/article/10.1007\%2Fs004 67-004-1732-5

10. Silverman G, Pedrosa I, Ellis J,et al.Bosniak Classification of Cystic Renal Masses, Version 2019: An Update Proposal and Needs Assessment. radiology.rsna.org. Radiology: Volume 292: Number 2-August 2019; 292:475-488. [https://doi.org/10.1148/radiol.2019182646]

11. Amnoff M. Fluid and Electrolyte Disturbances. In: Fauci A, Kasper D, Longo D, et al. Harrison's Principles of internal medicine, 18th ed. United States of America; The McGraw-Hill Companies, 2012. 